\title{
Field Desorption Mass Spectrometry of Antibiotics II. Peptide Antibiotics
}

\author{
Kazutaka Fukushima* and Tadashi Arai*
}

(Received April 10, 1979)

\begin{abstract}
Field desorption mass spectra of peptide antibiotics of various kinds are presented. In each case, a $\mathrm{M}^{+}$or $(\mathrm{M}+\mathrm{H})^{+}$peak of the antibiotics is obtained. Fragmentations available for an analysis of amino acid sequence occure in straight-chain peptide antibiotics.
\end{abstract}

\section{Introduction}

Mass spectra of antibiotics have been studied less than mass spectra of many other classes of natural products. This is partly because many antibiotics are nonvolatile compounds of high molecular weight.

Field desorption mass spectra, having now become a routine procedure, lead us to expect wide-spread fields of application. The utilization of field desorption mass spectrometry (FDMS) in the study of antibiotic field has been reported $^{1-b)}$. It can be seen in these reports that FDMS is the excellent method in determining molecular weights of a number of nonvolatile or thermally unstable antibiotics. Peptide and amino acid related antibiotics of various kinds have been isolated and some of them used as chemotherapeutics or biochemical tools. Mass spectrometry is one of the most rapid and sensitive techniques available for deducing molecular structure. In recent years mass spectrometry has often been shown to be the method of choice for determining the amino acid composition and sequence of various peptides ${ }^{\theta-9}$. From the point of view of an analysis of fragmentation and detection of molecular ion, we have studied the FDMS of a number of underived peptide antibiotics which exhibit a wide range of structural variation and molecular weight.

\section{Experimental}

Antibiotics.

All antibiotics were homogeneous on thin-layer chromatography. They are as follows.

*Department of Antibiotics, Research Institute for Chemobio-dynamics, Chiba University, 1-8-1 Inohana, Chiba, Japan. 
Amino acid related antibiotics: acidomycin (1), actinoboline (2), azaserine (3), cycloserine (4), 6-diazo-5-oxo-L-norleucine (5), enteromycin (6), and primocarcin (7).

Peptide antibiotics: leupeptin Ac (8), althiomycin (9), pepstatin $A(10)$, edeine $B_{1}(11)$, mikamycin $B(12)$, etamycin (13), valinomycin (14), bassianolide (15) and actinomycin $\mathrm{D}(16)$.

Other peptide antibiotics: griseoviridin(17) and astechrome(18).

\section{Apparatus.}

The FD mass spectra were obtained by the use of a double focusing JEOL.O1SG2 instrument fitted with a combined FD/ FI/EI ion source and a JMA 2000 data analysis system.

\section{Mass spectrometry.}

The mass scales and instrument conditions must be changed according to molecular weight of compounds. Antibiotics were divided according to molecular weight into three groups, less than 1,000, between 1,000 and 1,200, and between 1,200 and 1,500 .

In the first group, the mass scale was established by comparison with the EI spectrum of perflurokerosene obtained under identical scanning conditions. Especially in the case of (11), (12), (13) and (15), because of their high molecular weight, the calibration was performed by using of both perfluorokerosene and $\mathrm{n}$-heptyl-s-trazine. Instrument condition included: accelerating voltage of $+10 \mathrm{KV}$; cathode voltage of $-2 \mathrm{KV}$.

In the second group (valinomycin and astechrome), n-heptyl-s-triazine was used as standard material for calibration and mass spectra were obtained under the following instrumental conditions: accelerating voltage of $+6 \mathrm{KV}$; cathode voltage of $-4 \mathrm{KV}$.

In the last group (actinomycin D), n-nonyl-s-triazine was used for the same purpose as mentioned above and mass spectra were obtained under the following conditions: accelerating voltage of $+5 \mathrm{KV}$; cathode voltege of $-4 \mathrm{KV}$. Scanning rate was $10 \mathrm{sec}$ throughout the entire spectra. High temperature activated tungsten wire emitters were used and samples (approximately several $\mu \mathrm{g}$ ) were applied to the emitter by means of glass capillary technique.

\section{Results and discussion}

(I) Amino acid related antibiotics.

It has been shown that the FD method is an excellent technique for the determination of molecular weight of amino acids. It can be seen in these reports that in the FD mass spectra of the $\alpha$-amino acids a quasi-molecular ion $\mathrm{QM}^{+},(\mathrm{M}+1)^{+}$, instead of an $\mathrm{M}^{+}$was usually detected ${ }^{10-11}$.

In order to compare with informations obtained from general amino acids, FD mass spectra of seven amino acid related antibiotics of various kinds were measured. The antibiotics examined are presented with the emitter currents at which the spectra were recorded followed by $\mathrm{m} / \mathrm{e}$ values and relative intensities in Fig. 1.

From this figure, it is clear that the prominent $(\mathrm{M}+1)^{+}$or $\mathrm{M}^{+}$ions are given in all antibiotics at the best anode temperature (BAT) and, in similar manner as general amino acids, $(M+1)^{+}$ions are 


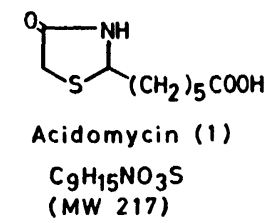

$15 \mathrm{~mA}: \mathrm{m} / \mathrm{e} 218(803)$

$16 \mathrm{~mA}: \mathrm{m} / \mathrm{e} 218(1000)$

$217(900)$

$100(131)$

$17 \mathrm{~mA}: \mathrm{m} / \mathrm{e} 217(762)$

$100(1000)$

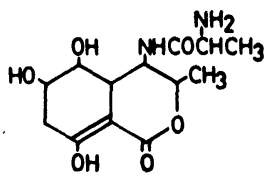

Actinobolin (2) $\mathrm{C}_{13} \mathrm{H}_{20} \mathrm{~N}_{2} \mathrm{O}_{6}$ (MW 300)

$17 \mathrm{~mA}: \mathrm{m} / \mathrm{e} 301(343)$

$20 \mathrm{~mA}: \mathrm{m} / \mathrm{e} 301(623)$

$300(1000)$

$265(574)$

240(60)
$\underbrace{0-\mathrm{NH}_{0}}_{\mathrm{NH}_{2}}$

Cycloserine (4)

$\mathrm{C}_{3} \mathrm{H}_{6} \mathrm{~N}_{2} \mathrm{O}_{2}$

(MW 102)

$15 \mathrm{~mA}: \mathrm{m} / \mathrm{e}$ 103(345)

$17 \mathrm{~mA}: \mathrm{m} / \mathrm{e} 174(1000)$ 102(1000)

$20 \mathrm{~mA}: \mathrm{m} / \mathrm{e} 129(1000)$

$$
\stackrel{\mathrm{N}}{\mathrm{N}}-\mathrm{CH}-\mathrm{O}-\mathrm{CH}_{2} \mathrm{CH}_{2} \stackrel{\mathrm{NH}}{\mathrm{CH}} \mathrm{COOH}
$$

6-Diazo-5-oxo-L-norleucine (5)

$\mathrm{C}_{6} \mathrm{H}_{9} \mathrm{~N}_{3} \mathrm{O}_{3}(\mathrm{MW} 171)$

$18 \mathrm{~mA}: \mathrm{m} / \mathrm{e} 172(1000)$

$171(245)$

$127(573)$

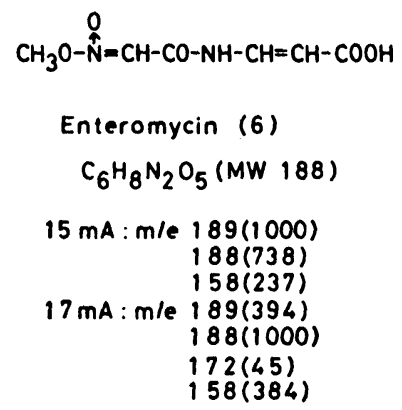

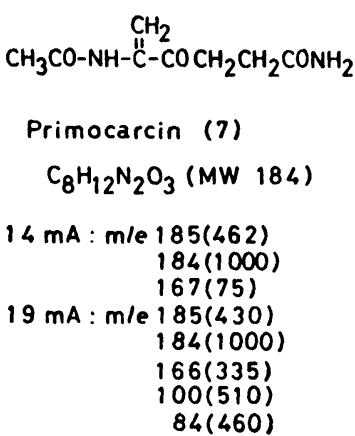

Fig. 1. Emitter currents and relative intensities in FD mass spectra of amino acid related antibiotics

preferentially observed to $\mathrm{M}^{+}$in most cases. Although two antibiotics, (3) and (5), produced the fragment ions ( $\mathrm{m} / \mathrm{e} 129$ and 127, respectively) due to loss of $\mathrm{COOH}$ from the $(M+1)^{+}$, there were no significant fragment ions in other cases. These data show that FDMS is very useful for determining the molecular weight of wide variety of naturally occuring amino acids.

\section{(II) Peptide antibiotics}

It is common technique to all antibiotics that mass spectra are obtained for each 1 $\mathrm{mA}$ rise in emitter current after BAT.

\section{Leupeptin Ac (8)}

Leupeptins, in which arginal is contained as carboxy terminal amino acid, are a series of enzyme inhibitors. Fig. 2 shows the FD spectra and chemical structure of leupeptin Ac. Fig. $2 \mathrm{c}$ is the spectrum that was averaged of seven spectra which were obtained at each emitter current from 17 to $23 \mathrm{~mA}$. At the BAT (Fig. 2a), $17 \mathrm{~mA}$, the $(M+1)^{+}$at $\mathrm{m} / \mathrm{e} 427$ is observed as base peak together with some fragment ions. At $21 \mathrm{~mA}$ (Fig. 2b) the abundance of ( $\mathrm{M}+$ $1)^{+}$ion is low, and the ion at $\mathrm{m} / \mathrm{e} 241$ provides the base peak, with the peak at $\mathrm{m} / \mathrm{e} 286$ being the second most intense. 

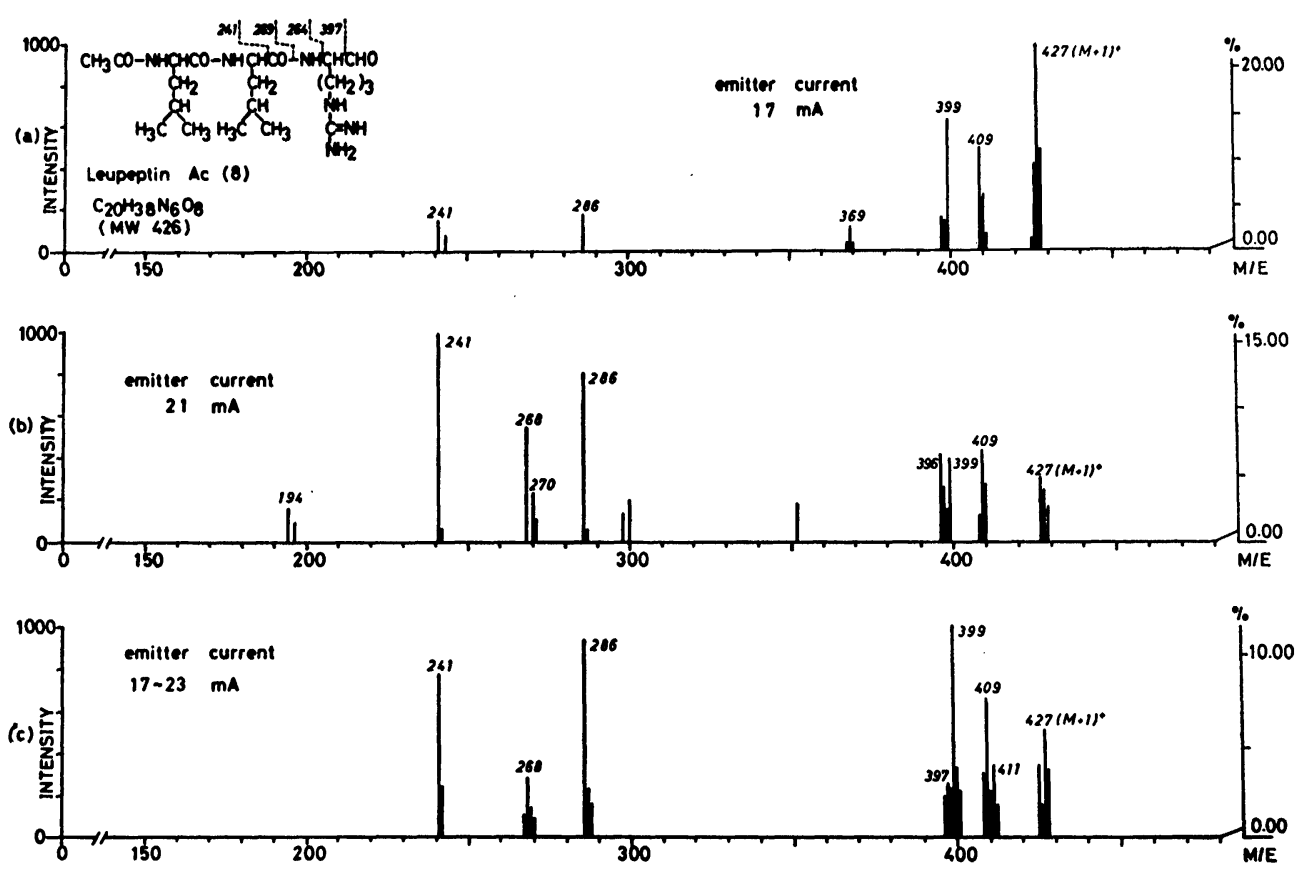

Fig. 2. FD mass spectra of Leupeptin Ac

As can be seen in these spectra, a cluster of peak is centerd at m/e 427 (M $+1^{+}$). In FDMS, mass peaks in the molecular ion region occur in clusters due to the addition of a hydrogen. In ions with high carbon count the $(\mathrm{M}+1)^{+},(\mathrm{M}+2)^{+}$ and $(\mathrm{M}+3)^{+}$arise partially from ${ }^{13} \mathrm{C}$ contributions and partially from hydrogen transfer to the $\mathrm{M}^{+}$and/or $(\mathrm{M}+1)^{+}$ions. The addition of hydrogen is due to surface reactions at the anode ${ }^{12}$. Less frequently peaks occur with hydrogen atoms abstracted from the ion during the surface reaction ${ }^{13}$. As a consequence of these surface reactions, ion masses cannot be predicted with a certainty of more than plus or minus two mass units.

Peaks occuring at $\mathrm{m} / \mathrm{e} 409\left(\mathrm{M}+1-\mathrm{H}_{2} \mathrm{O}\right)$, $399(397+2 \mathrm{H}), 286(284+2 \mathrm{H}), 269(268+\mathrm{H})$ and 241 in these spectra of leupeptin Ac may be related to the sequence of leupeptin Ac. The meaningful peaks were not observed in the region below m/e 150 .

\section{Althiomycin (9)}

Althiomycin is a peptide antibiotic composed of novel amino acids. Fig. 3 shows the FD spectra and chemical structure of althiomycin. At the BAT, $13 \mathrm{~mA}$, the intensive $(M+1)^{+}$ion, $m / e$ 440, was observed as base peak together with three fragment ions. The abundances of fragment ions increase with increasing emitter current (Fig. $3 \mathrm{~b}$ and $3 \mathrm{c}$ ). Sequence peaks due to cleavages in the backbone of the peptide occur at $\mathrm{m} / \mathrm{e} 328(327+\mathrm{H}), 310(312-2 \mathrm{H})$, $300(299+\mathrm{H})$ and $282(284-2 \mathrm{H})$. Other two fragment ions with moderate high intensity, 
Field Desorption Mass Spectrometry of Antibiotics (II)
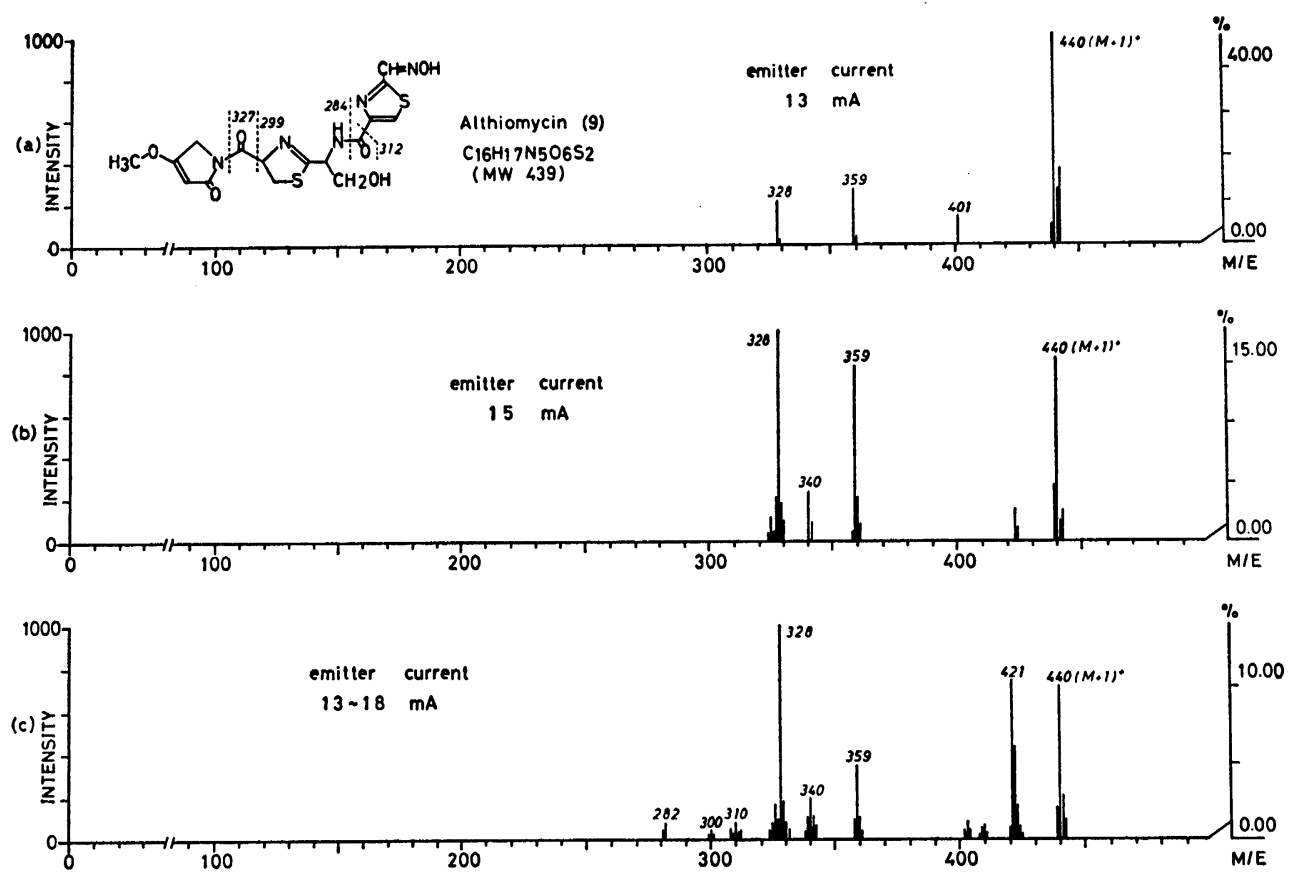

Fig. 3. FD mass spectra of Althiomycin
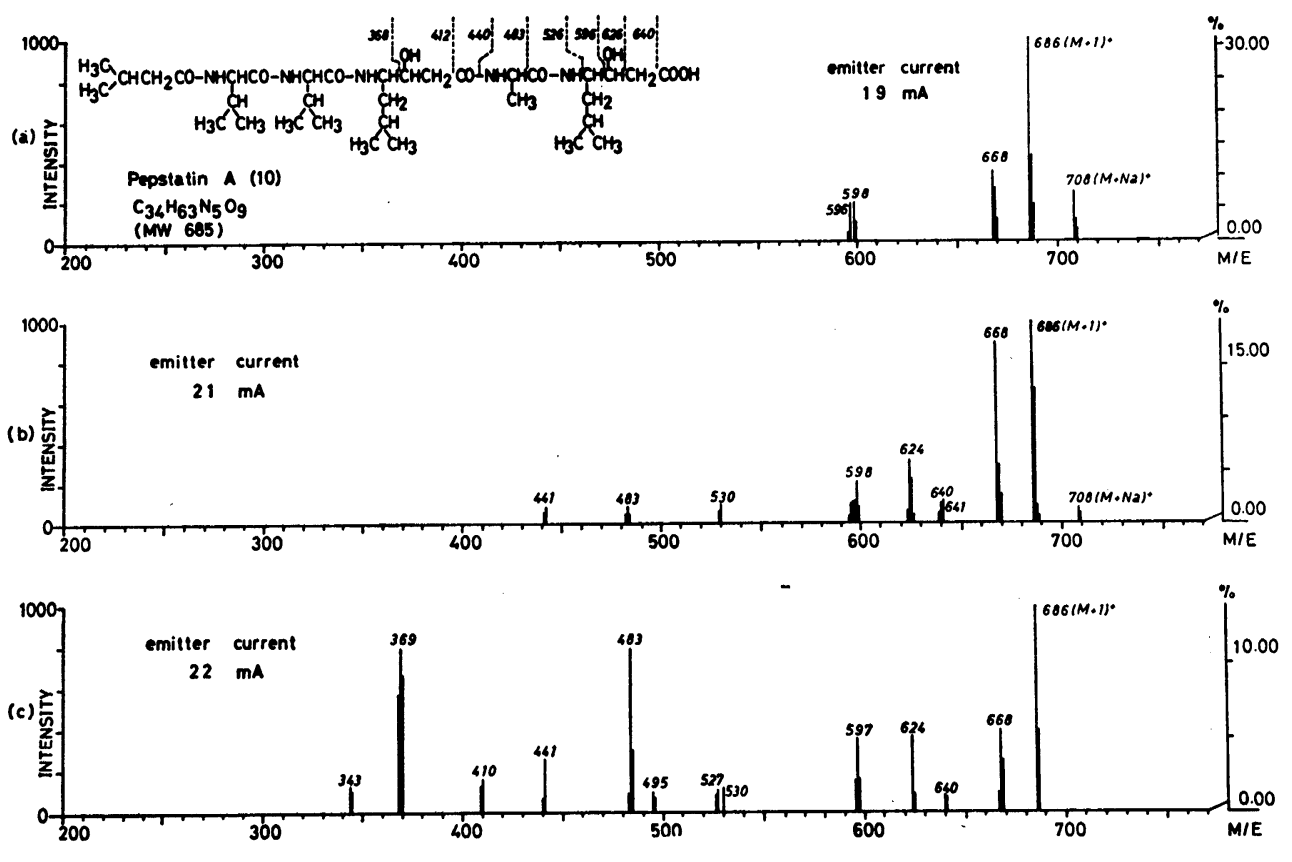

Fig. 4. FD mass spectra of Pepstatin A 
$\mathrm{m} / \mathrm{e} 359$ and 340 , cannot be assigned.

\section{Pepstatin A (10)}

Fig. 4 shows the FD spectra and chemical structure of pepstatin A. At the BAT (Fig. 4a) the prominent $(M+1)^{+}$ion, $\mathrm{m} / \mathrm{e} 686$, was appeared with the cluster ion $(\mathrm{M}+\mathrm{Na})^{+}, \mathrm{m} / \mathrm{e}$ 708. At $22 \mathrm{~mA}$, although the $(M+1)^{+}$ion provides still base peak, many meaningful fragment ions are detected. Sequence peaks due to the cleavage of the peptide backbone occur at m/e 640 and 483. Further sequence peaks are assigned at $\mathrm{m} / \mathrm{e} 597(596+\mathrm{H}), 527(526+\mathrm{H})$, $441(440+\mathrm{H})$ and $369(368+\mathrm{H})$. Sequence ions assigned to fragments containing two abstracted protons occur at m/e 624 (626$2 \mathrm{H})$ and $410(412-2 \mathrm{H})$.

\section{Edeine $B_{1}(11)$}

Fig. 5 shows the FD spectra and chemical structure of edeine $B_{1}$. At the BAT (Fig. 5a), the $(M+1)^{+}$ion at $m / e ~ 798$ was observed as base peak with the cluster ion, $(\mathrm{M}+\mathrm{Na})^{+}$, at $\mathrm{m} / \mathrm{e} 820$. At $18.5 \mathrm{~mA}$ (Fig. $5 \mathrm{~b}$ ) the ion at $\mathrm{m} / \mathrm{e} 756$ provides base peak and three other fragment ions are observed. However, these are not the sequence peaks due to cleavage in the backbone of edeine $B_{1}$.

\section{Mikamycin B (12), Etamycin (13)}

Fig. 6 and 7 show the FD spectra and the chemical structure of mikamycin B and etamycin, respectively. They are similar cyclic peptide antibiotics. At the BAT (Fig. 6a and 7), both antibiotics gave the prominent $(\mathrm{M}+1)^{+}$ion at $\mathrm{m} / \mathrm{e} 867$ and 879 , respectively. In etamycin such mass spectra as shown in Fig. 13 were obtained at more high emitter currents and fragmentations scarcely observed.

On the other hand, some reproducible fragment ions were observed at $18.5 \mathrm{~mA}$ in mikamycin B (Fig. 12b), but neither of them can be assigned to the sequence peaks.

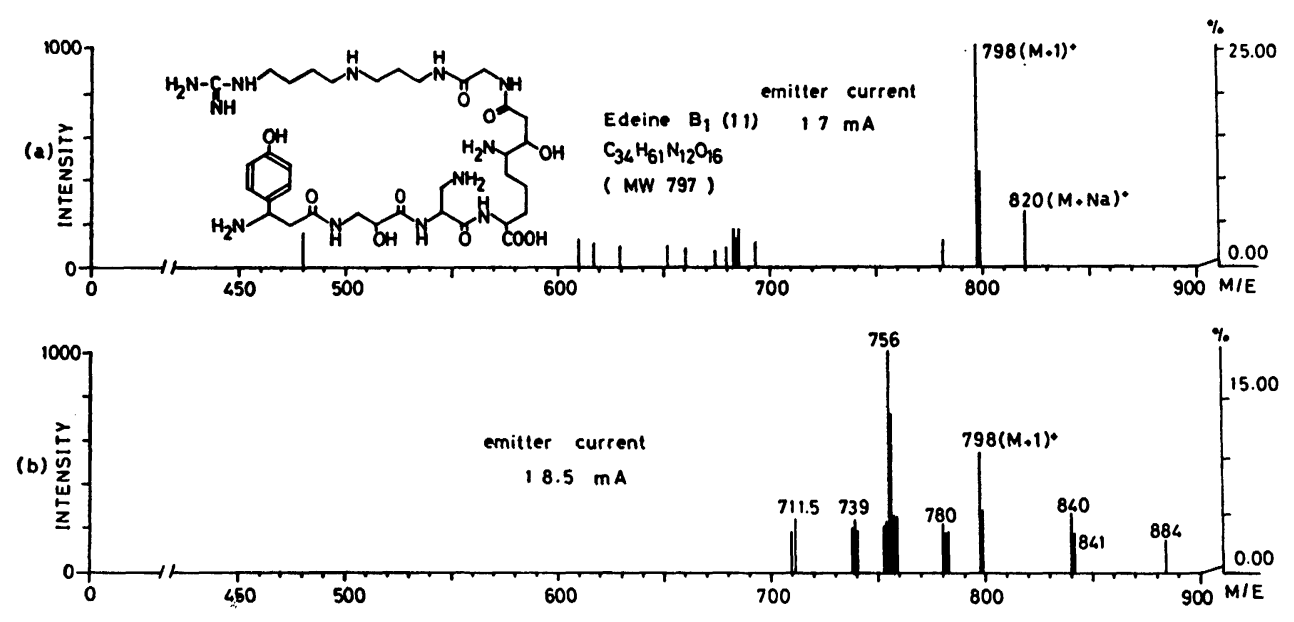

Fig. 5. FD mass spectra of Edeine $B_{1}$ 

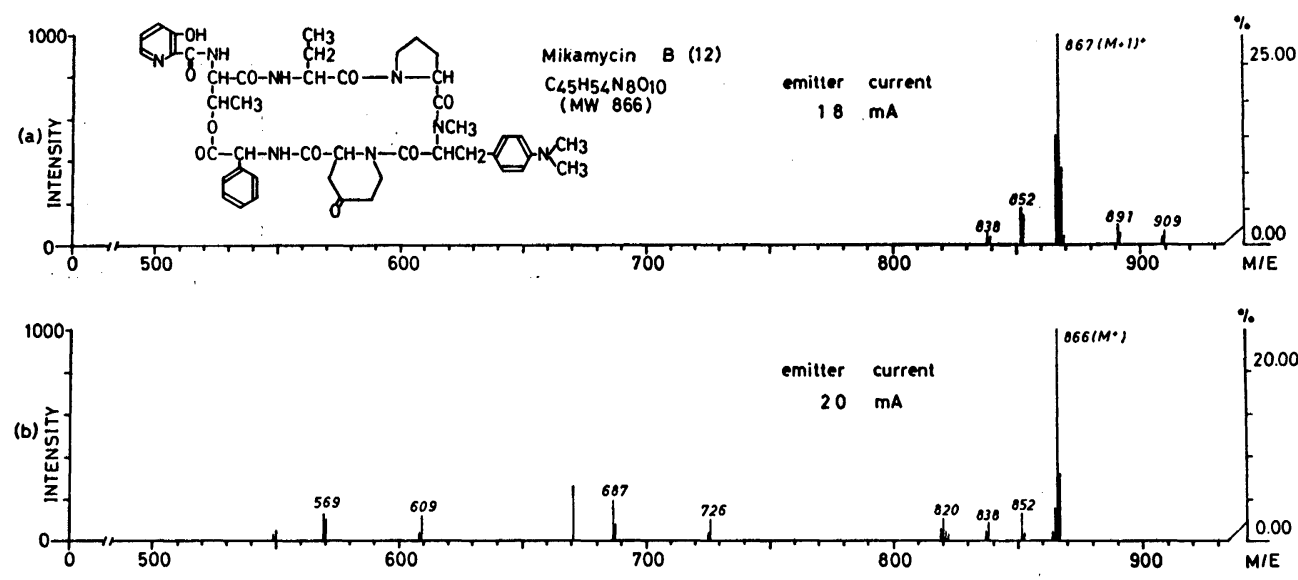

Fig. 6. FD mass spectra of Mikamycin B

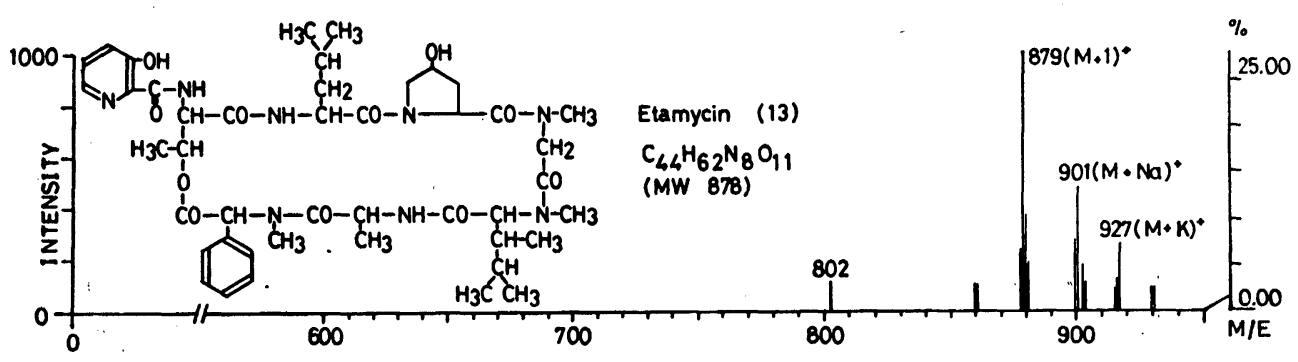

Fig. 7. FD mass spectrum of Etamycin

Valinomycin (14), Bassianolide (15)

Fig. 8 and 9 show the FD spectra at the BAT and chemical structure of valiomycin and bassianolide ${ }^{14)}$, respectively. As can be seen from the structure of both antibiotics, they are cyclic depsipeptide with high molecular weight. It can be seen in these figures that the intensive $\mathrm{M}^{+}$ ions, m/e 1,110 and 908, were observed as base peak in both cases and the fragmentations scarcely occured. This evidence means that cyclic peptide become to be thermally stable and less polar.

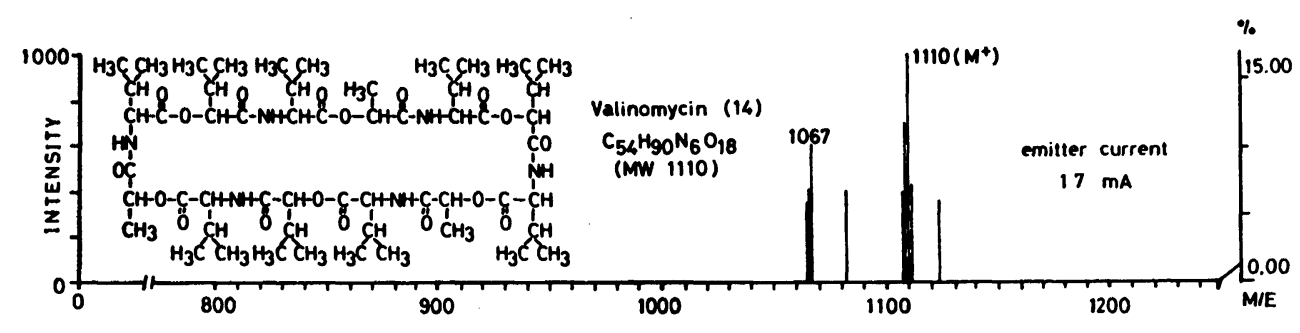

Fig. 8. FD mass spectrum of _Valinomycin 


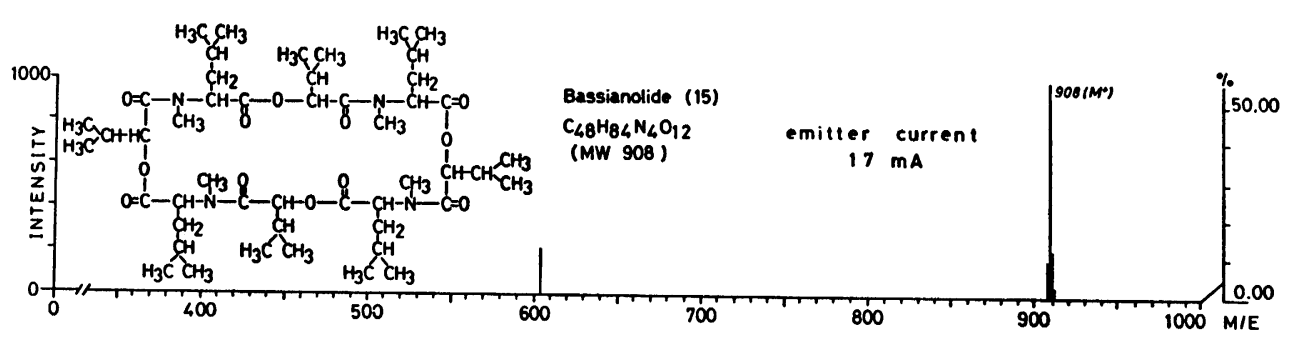

Fig. 9. FD mass spectrum of Bassianolide
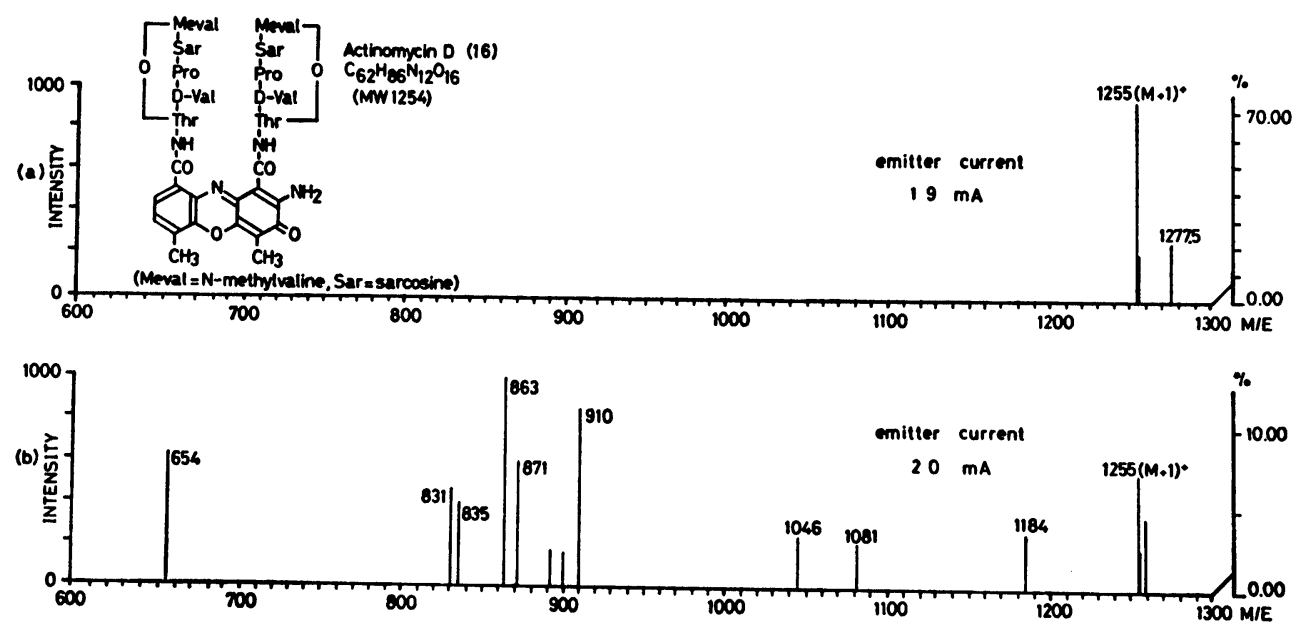

Fig. 10. FD mass spectra of Actinomycin D

Actinomycin D (16)

Fig. 10 shows the FD spectra and chemical structure of actinomycin D. Actinomycin $\mathrm{D}$ is an antibiotic which is constituted from two identical peptide lactone rings and the despeptido-actinomycin chromophor. At the BAT (Fig. 10a), the intensive ( $\mathrm{M}+$ $1)^{+}$ion at $\mathrm{m} / \mathrm{e} 1255$ is observed as base peak. At $20 \mathrm{~mA}$ (Fig. 10b) many fragment ions appeared, but neither of fhem can be assigned.

(III) Other peptide antibiotics.

Griseoviridin (17)

Fig. 11 shows the FD spectra and chemical structure of griseoviridin. Griseo viridin possesses a novel cyclic structure. At the BAT the prominent $\mathrm{M}^{+}$ion at $\mathrm{m} / \mathrm{e} 477$ is observed together with the cluster ion, $(\mathrm{M}+\mathrm{Na})^{+}$, at $\mathrm{m} / \mathrm{e} 500$ (Fig. 11a). Significant fragment ions were not obtained in all spectra measured at other different emitter current.

\section{Astechrome (18)}

Fig. 12 shows the FD spectrum and chemical structure of astechrome, which is a chelated fungal metabolite. The structure of astechrome has been estimated to be like as Fig. 12 by chemical studies ${ }^{15)}$. The 

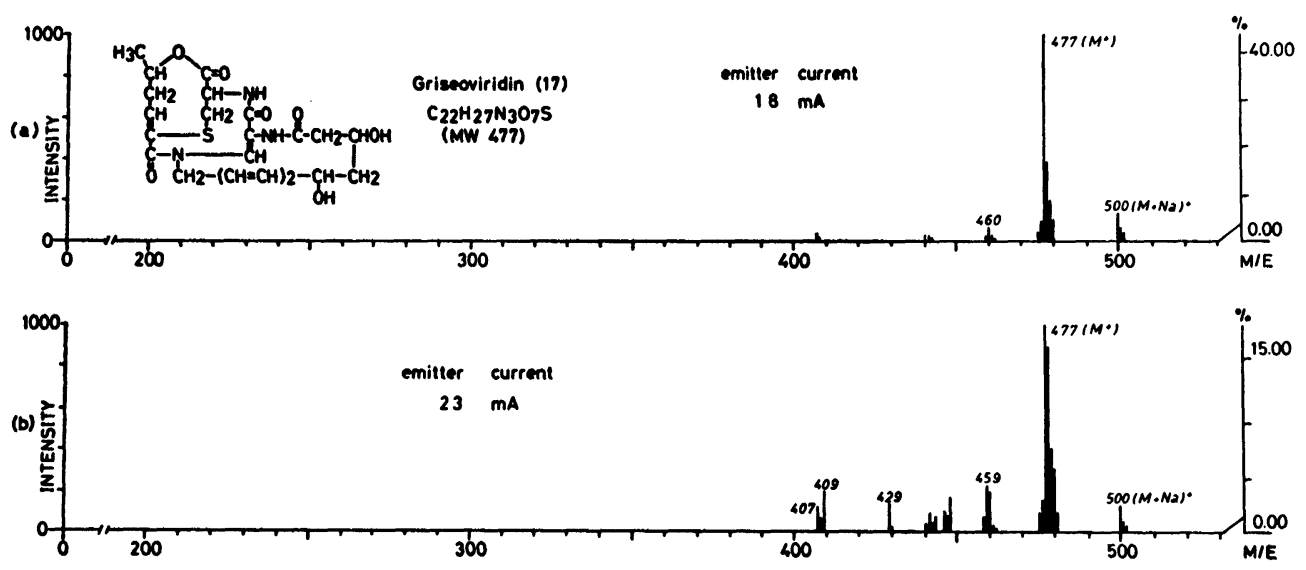

Fig. 11. FD mass spectra of Griseoviridin

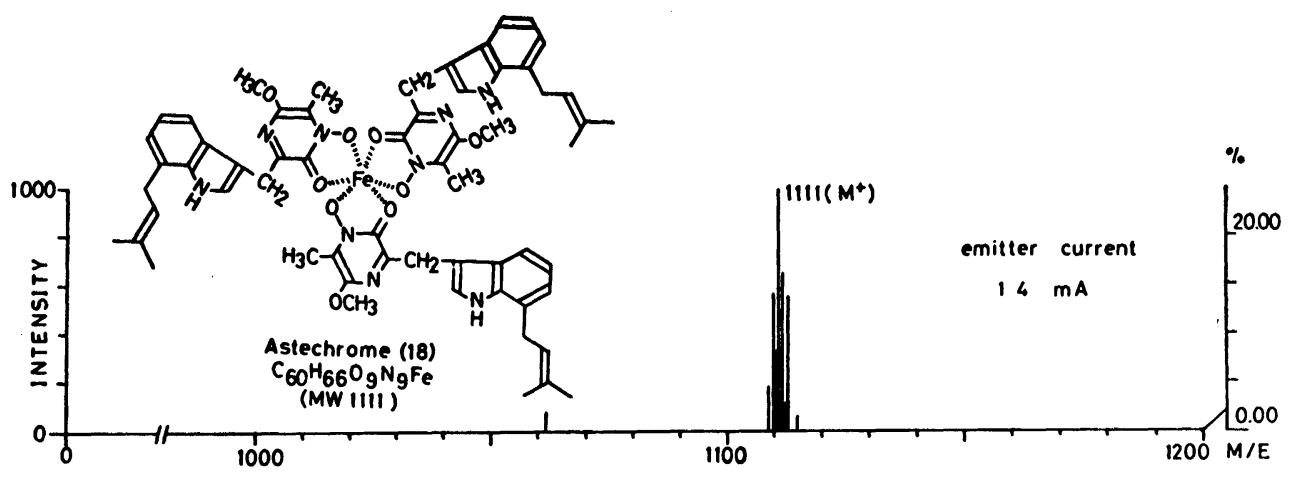

Fig. 12. FD mass spectrum of Astechrome

molecular ion was not observed by EIMS. However, FDMS give the prominent $\mathrm{M}^{+}$ ion at $\mathrm{m} / \mathrm{e} 1,111$. This result leads to the conclusion that the estimated structure for astechrome is correct.

\section{Conclusion}

In mass spectral studies of peptides, it is the main purpose to determine the molecular weight and the amino acid sequence. The most severe obstacle in these studies of peptides has been the notoriously low volatility of these compounds. EI and CIMS of peptides are normally obtained from the chemically modified material, since the compounds themselves usually show weak or no molecular ions.

From our data described here, it is clear that FDMS is a helpful technique in the peptide field. In the first place, from the spectra shown in Figs. 1-12, it should be emphasized that FDMS is the excellent method for determining the molecular weights of unmodified peptide and amino acid related antibiotics of various kinds. All cited antibiotics exhibited the intensive $\mathrm{M}^{+}$or $(\mathrm{M}+1)^{+}$as base peak at BAT. This typical pattern of FDMS is especially recognized in the cases of cyclic peptides and chelated compounds. 
Recently mass spectrometry has been used as one of the standard techniques for amino acid sequence analysis of peptides. For this purpose various methods of ionization, EI or $\mathrm{CI}$, have been applied and made to develop a general method. It was one of the purposes of this report to show that at appropriate anode temperatures the molecular ion could be obtained with sufficient fragment ions to allow in principle the sequencing of small peptides.

Sequence peaks in the EI mass spectra of peptides arise from ions formed by cleavages on either side of the carbonyl group of the peptide backbone ${ }^{16)}$.

A similar fragmentation pattern is seen in the straight-chain peptide antibiotics, (8), (9) and (10), investigated by FDMS. It is also shown in our data that a large number or fragment ions were obtained including the portions of peptide which contained not the carboxy terminal but $\mathrm{N}$ terminal amino acid. However, fragmentation of these peptides was insufficient to allow a sequence determination

Furthermore, there are such undefined problems as the addition or abstraction of hydrogens in surface reaction in FDMS. In order to determine the aimo acid sequence of peptides by FDMS, it is necessary to establish more certain general rule derived from the accumulation of many data. It is clear that FDMS is a good complement to EI and CIMS, therefore, combined use of these FDMS findings and informations available from other ionization methods such as EI and/or CI, will provide more effective and certain means for the sequence determination of peptides.

\section{Acknowledgement}

We thanks Prof. Y. Yamamoto (Kanazawa Univ.) and M. Suzuki (Meijo Univ.), for providing us with the sample of astechrome and edeine $B_{1}$, respectively.

\section{References}

1) K. L. Rinehart, Jr. and J. C. Cook, Jr., J. Antibiotics, 27, 1 (1974).

2) K. Fukushima and T. Arai, J. Antibiotics, 31, 377 (1978).

3) K. Fukushima and T. Arai, Mass Spectroscopy, 26, 197 (1978).

4) R. T. Parfitt, D. E. Games, M. Rossiter, M. S. Rogers and A. Weston, Biomed. Mass Spectrom., 3, 232 (1976).

5) K. Fukushima and T. Arai, submitted for publication in Mass Spectroscopy (Japan).

6). M. Barber, P. Jolles, E. Vilkas and E. Lederer, Biochem. Biophys. Res. Comm., 18, 469 (1965).

7) Y. Nakagawa, T. Nakazawa and J. Shoji, $J$. Antibiotics, 28, 1004 (1975).

8) H. U. Winkler and H. D. Beckey, Biochem. Biophys. Res. Comm., 46, 391 (1972).

9) S. Asante-Poku, G. W. Wood and D. E. Schmidt Jr., Biomed. Mass Spectrom., 2, 121 (1975).

10) H. U. Winkler and H. D. Beckey, Org. Mass Spectrom., 6, 655 (1972).

11) K. Fukushima, FD-MS Application Data vol. 102, JEOL Co., Ltd, Tokyo (1978).

12) A. J. B. Robertson, J. Sci. Instr., 7, 321 (1974).

13) H.D. Beckey, "Biochemical application of Mass spectrometry" G. R. Waller; ed. Wiley: New York, p. 795 (1972).

14) M. Kanaoka, A. Isogai, S. Murakoshi, M. Ichinoe, A. Suzuki and S. Tamura, Agr. Biol. Chem., 42, 692 (1978).

15) Y. Yamamoto, K. Nitta, S. Shimizu and S. Sato. Presented at the 97th Annual Meeting of the Pharmaceutical Society of Japan, Tokyo, Japan, April 1977, Abstracts, p. 189.

16) M. Senn, R. Venkataraghavan and F. W. McLafferty, J. Am. Chem. Soc., 88, 5593(1966).

\section{Keywords}

Field desorption mass spectrometry

Peptides

Antibiotics

Fragmentation

Amino acid sequence 